\title{
Effects of Abrasive Particle Type, Load and Sliding Distance on Micro-Abrasion Resistance of High Speed Steel Coated with AICrN or AITiN
}

\author{
Vedat Veli ÇAY* \\ Department of Airframes and Powerplants, School of Civil Aviation, Dicle University, 21280, Diyarbakir, Turkey \\ crossref http://dx.doi.org/10.5755/j02.ms.25776
}

Received 14 April 2020; accepted 18 June 2020

\begin{abstract}
High Speed Steel (HSS) specimen surfaces were coated with AlCrN and AlTiN via Physical Vapor Deposition (PVD) method for the micro-abrasion wear behavior testing. Wear tests were performed by fixed ball micro-abrasion wear equipment. During the micro-abrasion wear tests, $0.5,1$ and $1.5 \mathrm{~N}$ loads were applied for periods of 60 and 180 seconds. In these tests, different kinds of abrasives were used, as alumina $\left(\mathrm{Al}_{2} \mathrm{O}_{3}\right)$ and silicon carbide $(\mathrm{SiC})$. Two different particle sizes were used for each type of abrasive, which are F800 (mean size $6.5 \pm 1 \mu \mathrm{m}$ ) and F1200 (mean size $3.0 \pm 0.5 \mu \mathrm{m}$ ). During the wear tests, wear loss increased with increasing $\mathrm{SiC}$ and $\mathrm{Al}_{2} \mathrm{O}_{3}$ abrasive particle size. It was determined that the volume losses formed by $\mathrm{SiC}$ abrasive particles on $\mathrm{AlTiN}$ and $\mathrm{AlCrN}$ coatings to be higher than $\mathrm{Al}_{2} \mathrm{O}_{3}$ abrasive particles. Micro-grooving and micro-rolling wear mechanisms were observed when F800 and F1200 abrasive slurry were used, respectively. Volume losses increased with the increase in the applied load and the number of cycles. The AlCrN coatings exhibited better wear resistance than the AlTiN coatings. The applied test load had a significant effect on the wear mechanisms observed.
\end{abstract}

Keywords: micro-abrasion, coating, PVD, AlCrN, AlTiN.

\section{INTRODUCTION}

Today tooling supplies are generally used in the process of forming. Mostly all these tooling supply materials are made of high speed steel (HSS). Cutting and drilling performances of the HSS can be improved by the usage of hard coatings [1]. Thus, coatings play an important role on the performance of mechanic components of cutting devices in surface process [2]. Thus, the wear resistance of hot work tool steels [3] can be improved by using various surface engineering techniques. The wear and failure of HSS cutting tools have technological and economic impacts on industrial processing. A worn cutting edge impairs the quality of the machined and finished surfaces, resulting in low productivity and increased production costs. One of the adopted industrial approaches to decrease wear and increase the service life of cutting tools and the productivity is to coat the surface of cutting devices by hard coating layers [4]. Today, Physical Vapour Deposition (PVD) is the most widely used coating method used to coat HSS. The PVD technique provides an ideal combination of thin and hard coatings on HSS surfaces owing to the high hardness and wear resistance of the produced coatings in addition to chemically stability at high machining temperatures [5]. TiN, Ti (C, N), CrN and Al (TiN, CrN) hard coatings have been widely produced using the PVD technique. Among the coatings tested, $\mathrm{CrN}$ has an increasing popularity since the early 1980s as it presents favourable friction properties owing to its surface passivation capabilities and oxidation resistance [6-10]. The more recently commercialized AlCrN presents higher mechanical properties in addition to a higher oxidation resistance $[11,12]$. Thin and hard AlTiN coatings which is rich in aluminium present a high fatigue resistance at high temperatures. Also it is attractive due to its hardness and oxidation resistance at high temperatures [13].

As a result of their mentioned superior characteristics, these coatings find a wide application area in the coating industry. Recently, application of surface engineering techniques in forming and cutting tools has gained particular importance $[14,15]$, which also brings about the necessity for determination of these coatings' abrasive wear performance. The micro-abrasion wear test, introduced by Kassman et al., [15] is a widely used method for determining the abrasive wear resistance of thin hard coatings [7,17-19]. In the test, a hardened ball as the counter body is rotated on the specimen under a defined load, and meantime an abrasive slurry is added into the contact zone. Then, the formed crater track is examined using a profilometer and a microscope, thus the wear characteristics are determined [20,21]. The test is easy to perform and very effective for assessment of wear resistance of the materials, and it requires only a small portion of the sample surface. Mo et al. [22] studied the impact wear and micro-scale abrasion resistance of $\mathrm{CrN}, \mathrm{AlCrN}$ and AlTiN coatings deposited on cemented carbide by PVD technique. In micro-abrasion tests, they used $0.2 \mathrm{~N}$ load F1200 SiC abrasive particles and 5 different numbers of ball revolutions (N) of 10, 20, 50, 100 and 200. AlCrN coatings exhibited the best abrasive wear resistance among coatings. Batista et al [23] performed micro-abrasion tests of duplex and single-layered TiAlN, TiN and $\mathrm{CrN}$ coatings deposited on $\mathrm{H} 13$ steel by fixed-ball cratering technique. They used a fixed $0.25 \mathrm{~N}$ load and F1200 SiC abrasive particles on tests.

\footnotetext{
* Corresponding author. Tel.: +90-412-2411000; fax: +90-412-2411011.

E-mail address: vcay@dicle.edu.tr (V.V.Çay)
} 
They reported that all duplex coatings showed higher microabrasive wear resistance than their single-layered counterparts. The best improvement was achieved by the duplex (Ti,Al)N coating. Allsopp and Hutchings [24] used micro-scale abrasion testing methods to rank at room temperature and $350{ }^{\circ} \mathrm{C}$ of $\mathrm{TiCN}$, TiN and AlTiN coatings deposited on tool steel surfaces by directed arc evaporation. The authors concluded that the wear resistance values of the coatings at different temperatures are different and that the material order is similar and there is a change in the wear mechanisms at high temperature. The AlTiN coating tested was the most wear-resistant under all conditions.

Studies reviewed show that there is limited information about the comparative evaluation of micro abrasive wear behavior for different loads, different abrasives and abrasive sizes. Although some studies have been conducted on the micro-abrasion properties of $\mathrm{CrN}, \mathrm{CrAlN}$ and TiAlN coatings, limited work has been conducted to investigate such properties for high aluminum content (i.e. $\mathrm{AlCrN}$ and AlTiN) coatings which are now increasingly used on commercial cutting tools. The present work was therefore undertaken to investigate the wear resistance and wear mechanisms properties of AlCrN and AlTiN coatings deposited by PVD, with a focus on their tribological response in micro-abrasion.

\section{EXPERIMENTAL}

HSS cutting tools with $5 \times 20 \times 100 \mathrm{~mm}$ dimensions were used as the substrate material (C 0.90, Cr 4.10, V 1.9, W 6.40). The steel surface was polished up to a surface roughness of $R_{\mathrm{a}}<15 \mu \mathrm{m}$ and subjected to ultrasonic cleaning to remove debris particles. Surface roughness of HSS substrate was measured by using Mitutoyo Surface Roughness Tester device according to EN ISO 4287. Then the samples were heated in vacuum and bombarded with Ar+-ions before the coating process. Customized $\mathrm{Al}_{67} \mathrm{Ti}_{33}$ (at.\%) and $\mathrm{Al}_{70} \mathrm{Cr}_{30}$ targets were used to fabricate the AlTiN and AlCrN coatings, respectively. Deposition took place in an $\mathrm{N}_{2}$ (purity $>99.99 \%$ ) atmosphere with $4.0 \times 10^{-2}$ mbar partial pressure. During deposition, the temperature of the specimens was elevated to around $600{ }^{\circ} \mathrm{C}$ for the AlTiN coating and $500{ }^{\circ} \mathrm{C}$ for the AlCrN coating. DC-bias voltage and target current for the substrate were $-80 \mathrm{~V}, 150 \mathrm{~A}$ respectively and deposition time was $15 \mathrm{~min}$. After the coating process, the specimens were cut into the dimensions of 5 (thickness) $\times 20$ (width) $\times 20$ (length) $\mathrm{mm}$ for the wear tests.

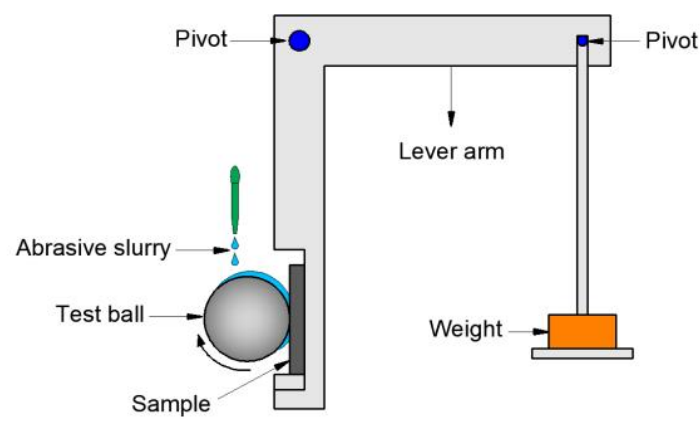

Fig. 1. Schematic diagram of fixed-ball test
After the coating process, a fixed-ball micro-abrasion wear test was carried out on each of the samples. In this method, (Fig. 1) the ball is rotated directly by clamping the ball in a split drive shaft which allows the balls to be removed and replaced easily. From the side the sample was pressed on the rotating ball using the specified loads placed on the weight pan. The ball, $25.4 \mathrm{~mm}$ in diameter, used during the test was made of AISI 52100 steel. During the abrasive wear tests, two types of abrasives were used, namely $\mathrm{SiC}$ and $\mathrm{Al}_{2} \mathrm{O}_{3}$. Abrasives with different particle sizes were used with the following designations: F800 $(6.5 \pm 1 \mu \mathrm{m})$ and F1200 $(3.0 \pm 0.5 \mu \mathrm{m})$, according to FEPAStandard $42-2: 2006$. The abrasive slurry was produced by adding $20 \mathrm{~g}$ abrasive particles in $75 \mathrm{ml}$ distilled water. The ball rotation speed was selected as $140 \mathrm{r} / \mathrm{min}$ (calculated as $0.099 \mathrm{~m} / \mathrm{s}$ ). All the tests were performed within the distance of 140 and 420 cycle, and under 0.5, 1 and $1.5 \mathrm{~N}$ loads. Each test was repeated three times to ensure reproducibility of the results. Abrasive solution was dropped on the abrasive ball with $20 \mathrm{~s}$ intervals. After the abrasion process was completed, the sample surfaces were cleaned up with alcohol and 6 bar compressed air was applied. All of the resulting scars had a quasi-uniform spherical shape. The volume of the removed material was computed in accordance with Eq. 1 [25-27]:

$V \approx \frac{\pi b^{4}}{64 R}$

where $V$ denotes the volume of the wear loss; $b$ is the diameter of the outer crater; and $R$ is the radius (in $\mathrm{mm}$ ) of counter-body. This equation is valid only for the case where the following condition applies; $b \ll R$. All measured diameters were received from at least 5 different points and then they were averaged to determine the crater diameter. A Huvitz 5800 3D profilometer was used to measure the diameters of wear craters.

After the micro-abrasion tests, the wear craters were studied using Scanning Electron Microscopy (SEM; TESCAN MAIA3 XMU and Energy Dispersive X-ray (EDX) spectroscopy, and microhardness tests were performed under $25 \mathrm{~g}$ load using QNESS Q10 microhardness tester. The X-ray diffraction (XRD) analyses were carried out using a Rigaku DMAX II X-ray diffractometer with $\mathrm{Cu} \mathrm{K} \alpha$ radiation between $30^{\circ}-70^{\circ} 2 \theta$ angles. The abrasion wear behaviour of the coatings was assessed on the basis of their mechanical properties.

\section{RESULTS AND DISCUSSION}

\subsection{Microstructure characterization}

Fig. 2 shows the cross-sectional SEM images of the bottom surface layer of the obtained thin coatings These images show that the AlCrN and AlTiN coatings exhibited a good adhesion to HSS substrates, also a dense and homogenous microstructure without delamination or structural flaws along the interface. The thickness and hardness values of the AlCrN and AlTiN coatings are around $3.8-4 \mu \mathrm{m}, 3300 \mathrm{HV}$ and $3.6-3.8 \mu \mathrm{m}, 2850 \mathrm{HV}$, respectively. 


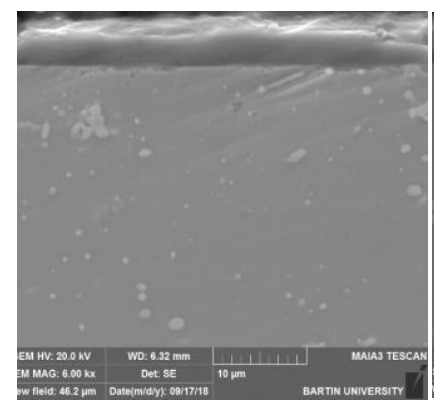

a

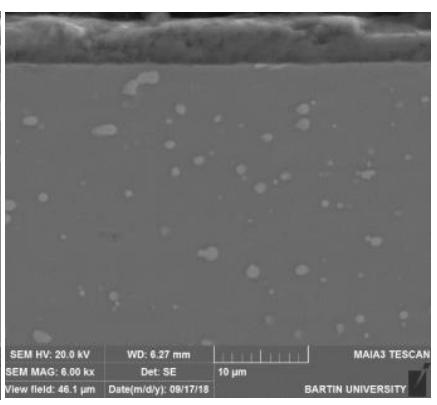

b
Fig. 2. SEM cross section images of samples: a-AlTiN; $\mathrm{b}-\mathrm{AlCrN}$

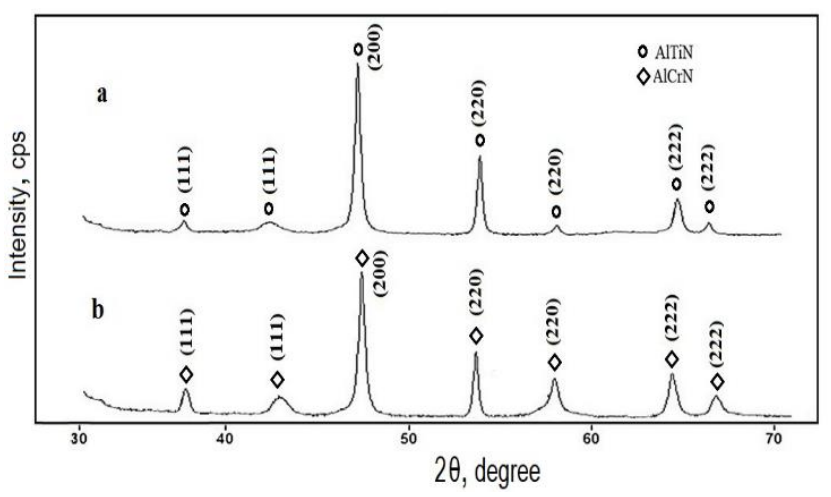

Fig. 3. X-ray diffraction patterns from the surface of $\mathrm{AlCrN}$ and AlTiN coated HSS samples

The XRD analysis of the AlCrN coating indicates the existence of a crystal $\mathrm{NaCl}$ structure (Fig. 3 a). Cubic form is desired when compared to the hexagonal form as it contains more $\mathrm{Al}$. $\mathrm{Al}_{\mathrm{x}} \mathrm{Cr}_{1-\mathrm{x}} \mathrm{N}$ coatings present high hardness, improved resistance to oxidation and favorable tribological properties to the extent that the cubic crystal structure is maintained in the presence of a high $\mathrm{Al}$ content [28, 29]. Effective micro-abrasion resistance is thus possible in the presence of a cubic form with high $\mathrm{Al}$ content. As seen from Fig. 4 b, aluminum atoms were partly replaced with titanium atoms. As understood clearly here, AlTiN coating's structure depends upon the structure of NaCl-AlN [30]. The increase in the aluminum content significantly improves the thermal stability and hardness values [31]. It was difficult to see a soft hcp-AlTiN phase in the XRD results [14].

\subsection{Micro-abrasion wear results}

In the micro-abrasion tests, 3 different loads, 2 wear cycles and 2 types of abrasives were used on the specimens. The wear losses obtained are given in Fig. 4. A higher volume loss was observed on the specimens during the tests when the slurry with $\mathrm{SiC}$ content was used. The abrasive effect of $\mathrm{Al}_{2} \mathrm{O}_{3}$ powders is relatively less than that of $\mathrm{SiC}$. This can be ascribed to the 1.5 times higher hardness of $\mathrm{SiC}$ particles than $\mathrm{Al}_{2} \mathrm{O}_{3}$ particles [32, 33]. Hardness is defined as the resistance of a material to plastic deformation. In this regard, hardness is one of the most important parameters and it must be taken into account when evaluating the wear resistance of tribo-pairs. Several parameters including load, abrasive concentration, type and size have been reported to be effective on the formation of abrasive wear mechanism.

As previously reported $[27,34]$, one of the most important factors for abrasive wear is considered as the ratio between the abrasive particle's hardness ( $\mathrm{Ha}$ ) and the abraded surface's hardness $(H \mathrm{~s})$.
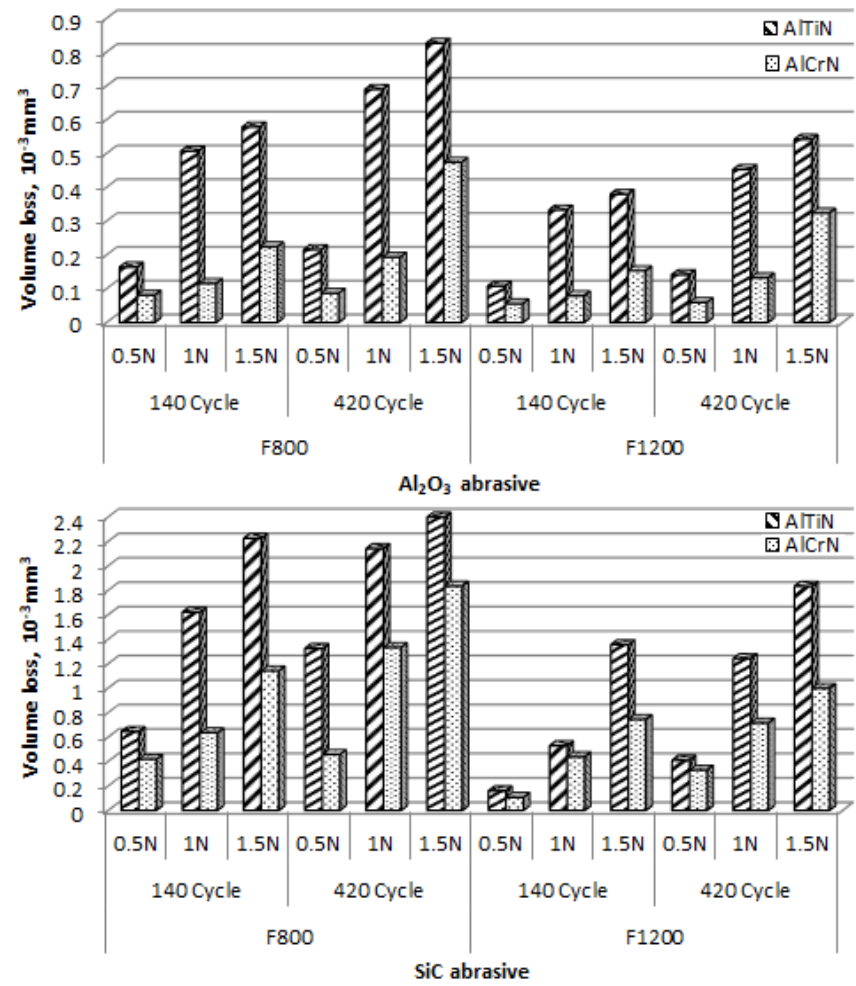

Fig. 4. Graph of volume loss depending on $\mathrm{Al}_{2} \mathrm{O}_{3}$ and $\mathrm{SiC}$ abrasive type

When $\mathrm{Hs} / \mathrm{Ha}$ is less than 1.3 , the particle wear occurs. Therefore, the ratios below 1.3 results in an increased wear loss. In this work, it was observed that the wear resistance is increased by increasing the coating hardness. The ratios of $\mathrm{Hs} / \mathrm{Ha}$ were obtained as $1.43,1.95,1.24,1.73$ for $\mathrm{AlCrN} /$ $\mathrm{SiC}, \mathrm{AlCrN} / \mathrm{Al}_{2} \mathrm{O}_{3}, \mathrm{AlTiN} / \mathrm{SiC}, \mathrm{AlTiN} / \mathrm{Al}_{2} \mathrm{O}_{3}$ respectively. In this work, the AlTiN coating had a low AlTiN/SiC ratio with about 1.24 , thus leading to a low abrasion resistance. The best abrasion resistance was obtained with the $\mathrm{AlCrN} / \mathrm{Al}_{2} \mathrm{O}_{3}$ ratio. However, it is stated by Adesina et al [10] that the best wear resistance of the between TiN, CrN, AlTiN and AlCrN hard coatings was on the AlCrN coating. That they reported the wear resistance performances of other coatings, AlTiN, CrN and TiN, respectively, according to the coating hardness. Many authors stated in their studies that hard coatings exhibit lower wear loss $[9,11,18,22,23]$. It was also observed that the hardness of the surface film is effective on the micro abrasion resistance of the specimens. But, the role of the coating decreases when the film layer is punctured or damaged by the abrasive particles. The wear mechanism observed on the specimen surface is closely related with the movement of the hard particles in solution between the ball and the surface. If the abrasive particles are stuck between the specimen surface and the ball, their movement is restricted that results in the tracks being parallel to each other. This is called as two-body abrasion and these tracks are called as grooves. If there is no restriction in the movement of the particles between the surface and the ball, in this case, the wear mechanism is termed as three-body abrasion. The morphology of the tracks is then changed and they occur via rolling [35-38]. 


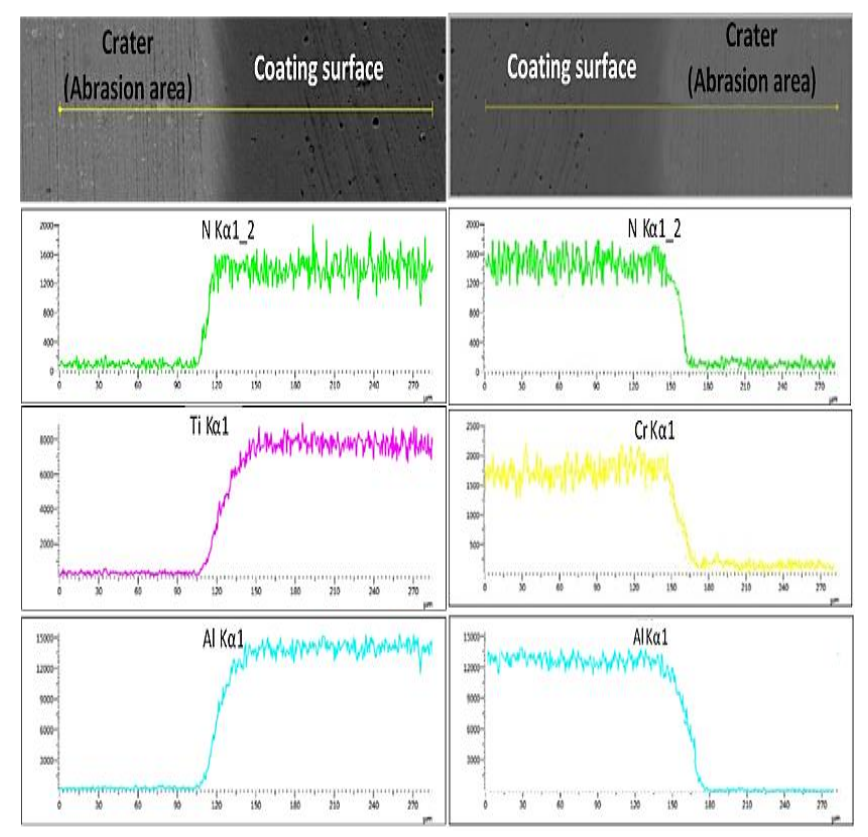

a

b

Fig. 5. EDX line analysis of coating layers: $a-T i A l N ; b-A l C r N$

Fig. 5 shows the EDX line spectra of the test specimens. The EDX analysis gives an idea about the elements that are likely to be available in the coating layer. In Fig. 5 a, the deposited $\mathrm{Al}, \mathrm{Ti}$ and $\mathrm{N}$ elements for TiAlN are homogeneously distributed throughout the coating as intended. Similarly, the $\mathrm{Al}$ and $\mathrm{Cr}$ elements appear to be homogeneous and stable in the coating layer (Fig. 5 b).

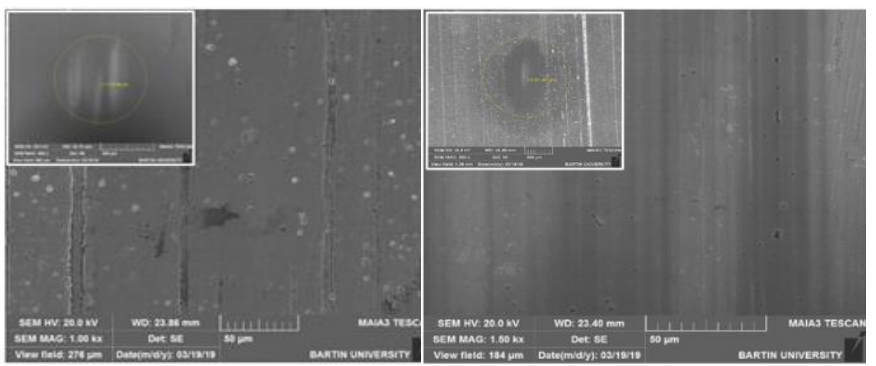

a

Fig. 6. SEM micrographs of the worn surfaces of AlCrN sample under $1.5 \mathrm{~N}$ and 420 cycle for abraded with $\mathrm{Al}_{2} \mathrm{O}_{3}$ : $\mathrm{a}-\mathrm{F} 800 ; \mathrm{b}-\mathrm{F} 1200$

As seen from Fig. $6 \mathrm{a}$ and $\mathrm{b}$, there is no abrasion on the surface of the specimen.

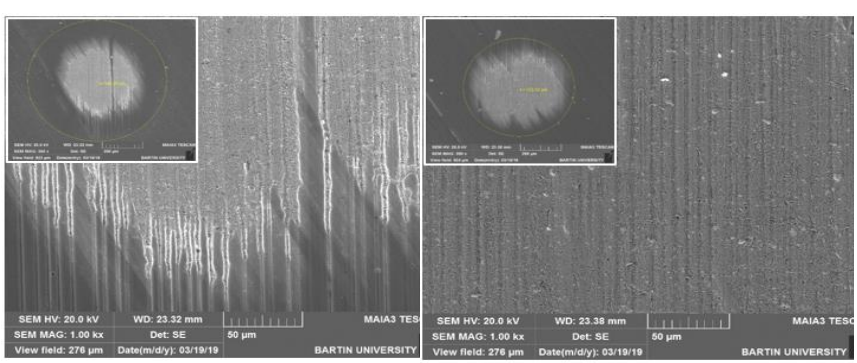

a

$\mathrm{b}$

Fig. 7. SEM micrographs of the worn surfaces of AlTiN sample under $1.5 \mathrm{~N}$ and 420 cycle for abraded with $\mathrm{Al}_{2} \mathrm{O}_{3}$ : $\mathrm{a}-\mathrm{F} 800 ; \mathrm{b}-\mathrm{F} 1200$
$\mathrm{Al}_{2} \mathrm{O}_{3}$ undertakes the role of polishing. The particles did not sink into the coated layer due to the hardness of specimen coated with $\mathrm{AlCrN}$. The particles also did not induce any damage on the specimen surface. But, F800 particles induced point and linear defects in micro level on the specimen surface (Fig. 6 b).

It was observed that when SEM wear track of AlTiN specimen was subjected to micro-abrasion test in the same condition, the coating layer damaged more as seen in Fig. 7. The hardness of the coating layer is effective on the wear morphology. F800 particles partly form grooves on the craters as seen in Fig. 7 a. In both coatings, micro-rolling abrasion can be seen as the dominant wear mechanism. Micro-grooving abrasion mechanism with the micro-rolling abrasion mechanism was also seen. However, when the morphology formed by $\mathrm{Al}_{2} \mathrm{O}_{3}$ F1200 is examined, microrolling can be considered as the dominant wear mechanism as also indicated in Fig. 7 b.

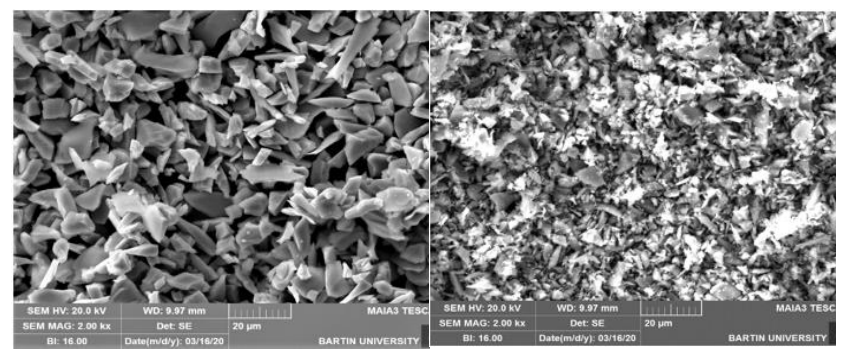

a

b

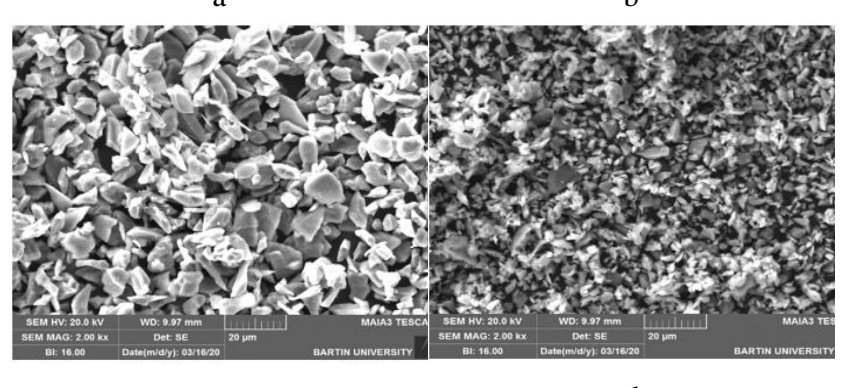

c

d

Fig. 8. Abrasive particle morphologies: a-SiC F800; b-SiC F1200; c- $\mathrm{Al}_{2} \mathrm{O}_{3}$ F800; d- $\mathrm{Al}_{2} \mathrm{O}_{3}$ F1200

It is known that, aside from particle hardness, particle size distribution and particle shape can also be effective on the wear behavior $[27,39,40]$. When F800 and F1200 abrasive particle sizes are evaluated in $\mathrm{Al}_{2} \mathrm{O}_{3}$ abrasive slurry, it is seen that F800 causes higher volume losses. When the SEM photographs of the abrasives are examined, it is seen that $\mathrm{SiC} \mathrm{F800} \mathrm{and} \mathrm{Al}_{2} \mathrm{O}_{3} \mathrm{~F} 800$ abrasive particles are the same size (Fig. $8 \mathrm{a}, \mathrm{c}$ ). However, it is noteworthy that the F1200 abrasive particles are mixed with smaller particles due to the difficulty of sieving (Fig. $8 \mathrm{~b}$, d). These small size particles remain between the ball and the counter surface during the abrasion process, and because of the insufficient size for abrasion, the particle cannot penetrate into the counter surface. In addition, it is possible to think that these particles, which have a size between $1-3 \mu \mathrm{m}$, are broken down and displaced from the system due to their hard structure.

Another approach is that, these small particles intervene between the counter surface and the abrasives (with adequate particle size) that are meant to undertake the actual abrasion work, thus reducing their abrading capability. 
Another view is that the combination of particles of different sizes will increase the density of the abrasive particles per unit area, which may lead to an increased load carrying resistance.

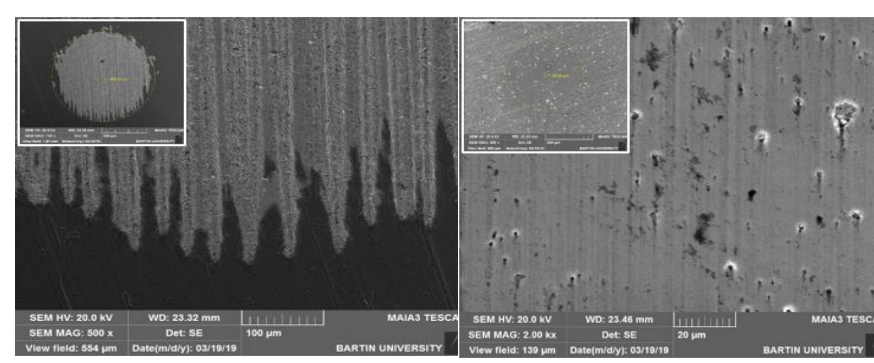

a b

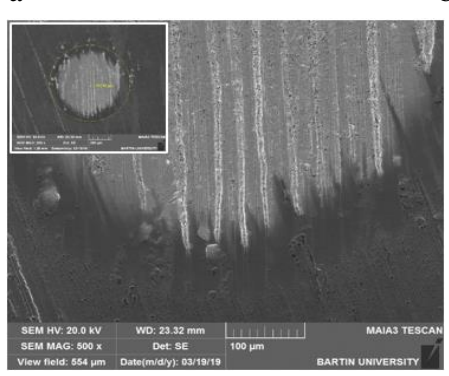

$\mathrm{c}$

Fig. 9. SEM micrographs of the worn surfaces of AlCrN sample under $1.5 \mathrm{~N}$ and 420 cycle for abraded with SiC: a-F800; $\mathrm{b}$-F1200; c-under $0.5 \mathrm{~N}$ F800

Fig. $9 \mathrm{a}-\mathrm{c}$ shows the SEM micrographs of the wear scratch of the $\mathrm{AlCrN}$ coatings corresponding to the increased abrasive particle size. In Fig. 9 a, the 500X magnified view of the crater shows that the grooves are clearly formed. The grooves being parallel to each other indicate that a two-body wear mechanism took place. With the contact of the abrasive slurry to the surface of the ball, it is seen that the abrasive particles slip through the formed grooves. It caused great damage and created a trace of wear. This indicates that the coating is both hard and has strong adhesion to the surface. It was observed that the damage caused was reduced by decreasing the load applied on the sample (Fig. 9 c, $0.5 \mathrm{~N}$ ), partial micro-scratches were formed on the surface and the damage was more superficial. F1200 SiC abraded specimens showed no damage to the coating (Fig. 9 b). The abrasive particles are rolled between the ball and the coating layer, which only serves to polish the hard coating layer. Micro-scratches have formed on the surface due to the settling of abrasive particles into the small-sized defects on the coating layer.

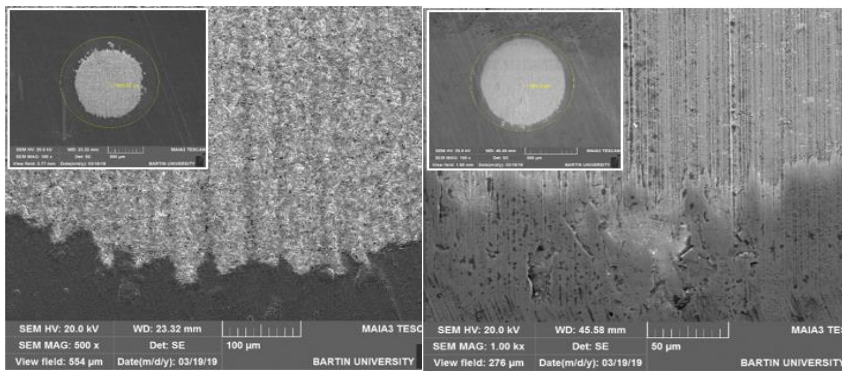

a

b

Fig. 10. SEM micrographs of the worn surfaces of AlTiN sample under $1.5 \mathrm{~N}$ and 420 cycle for abraded with SiC: $\mathrm{a}-\mathrm{F} 800 ; \mathrm{b}-\mathrm{F} 1200$
Fig. 10 shows the SEM micrographs of the wear scars on the AlTiN coatings related with the abrasive particle sizes. It can be concluded by observing the volume loss graphs presented in Fig. 5 that the abrasive particle size has a significant effect on the wear results and mechanisms that occur during the wear process. It was seen that the groove depth is higher for F800 abrasive particles, and lower for the F1200. On the coatings subjected to the tests with greater abrasive particle sizes, micro-rolling abrasion can be seen as the dominant mechanism (Fig. 10 a). Micro-rolling abrasion mechanism as well as the micro-grooving abrasion mechanism could also be seen. However, when the morphology of the samples subjected to F1200 is examined, micro-scratches can be considered as the dominant wear mechanism (Fig. 10 b).

It is understood that the transition from groove formation to rolling abrasion occurred during the microabrasion wear test, depending on the load per particle, abrasive particle size, slurry concentration and abrasive type used. It can be said that the hardness of the wear surfaces also significantly affects the transition from the groove to rolling wear. It has been found that coating hardness has a significant effect on the abrasion resistance, such that, abrasive particles' ability to scratch the coating surface is reduced by increasing hardness of the coating. As indicated by the findings, owing to its higher hardness the $\mathrm{AlCrN}$ coating exhibited a significant increase in the abrasion resistance as compared to the AlTiN coating.

\section{CONCLUSIONS}

AlCrN and AlTiN thin hard coatings were produced by the PVD technique on HSS tool steel and micro-abrasion behaviors were studied. The coated samples were subjected to fixed-ball micro abrasion wear tests using $\mathrm{SiC}$ and $\mathrm{Al}_{2} \mathrm{O}_{3}$ particles of F800 and F1200 grit size for periods of 140 and 420 cycles under $0.5,1$ and $1.5 \mathrm{~N}$ loads. The main results can be summarized as follows:

1. The AlCrN coating showed the best wear resistance under all test conditions. This is attributed to the higher hardness of the coating layer.

2. The abrasive particle type and size have significant effect on the resulting wear performance and wear mechanisms. The highest volume losses were observed on the samples abraded with SiC F800 abrasive, while the lowest volume losses were observed with F1200 $\mathrm{Al}_{2} \mathrm{O}_{3}$ abrasive. The dominant wear mechanism was micro-grooving in the tests performed with $\mathrm{SiC}$ and $\mathrm{Al}_{2} \mathrm{O}_{3}$ (with $\mathrm{F} 800$ grit size). for AlTiN coatings, whereas the dominant wear mechanism was microrolling in the tests performed with the $\mathrm{Al}_{2} \mathrm{O}_{3}$ coating (with F1200 grit size). For AlCrN coatings subjected to wear tests with $\mathrm{F} 800 \mathrm{SiC}$ and $\mathrm{Al}_{2} \mathrm{O}_{3}$ abrasives, the dominant wear mechanism was micro-grooving, whereas micro-rolling and polishing mechanisms were observed in the case of in $\mathrm{F} 1200 \mathrm{SiC}$ and $\mathrm{Al}_{2} \mathrm{O}_{3}$ abrasives.

3. In the tests performed with F800 abrasive particles, higher wear losses were determined as compared to F1200 abrasive particles. This is attributed to the reduction in the abrasive particles size through crumbling. 
4. With the increasing test cycle, wear losses also increased. In the tests made with 140 cycles, microgrooves formed by F800 particles were more pronounced. In the 420 cycle, micro-grooves were not very pronounced and decreased.

5. Wear loss values increased with increasing load. The increase in load enabled the abrasive particles to penetrate into the surface more easily and thus to cause more damage on the surface.

\section{REFERENCES}

1. Mokas, N., Boulanouar, L., Amirat, A., Gautier, L. Effect of Hardening on The Machinability Of C22 Steel Under Drilling Operations Using Twist HSS Drill Bit The International Journal of Advanced Manufacturing Technology 96 (9-12) 2018: pp. 3227-3234. https://doi.org/10.1007/s00170-018-1818-z

2. Brostow, W., Hagg Lobland, H.E. Materials: Introduction and Applications. John Wiley \& Sons. 2016.

3. Khan, S.A., Nazir, A., Mughal, M.P., Saleem, M.Q., Hussain, A., Ghulam, Z. Deep Hole Drilling of AISI 1045 via High-Speed Steel Twist Drills: Evaluation of Tool Wear and Hole Quality The International Journal of Advanced Manufacturing Technology 93 (1-4) 2017: pp. $1115-1125$. https://doi.org/10.1007/s00170-017-0587-4

4. Cho, I.S., Amanov, A., Kim, J.. The Effects of Alcrn Coating, Surface Modification and Their Combination on The Tribological Properties of High Speed Steel Under Dry Conditions Tribology International 81 2015: pp. 61-72. https://doi.org/10.1016/j.triboint.2014.08.003

5. Çöl, M., Kir, D., Erişir, E. Wear and Blanking Performance of AlCrN PVD-coated Punches Materials Science 48 (4) 2013: pp. $514-520$.

6. Gök, M.S., Erdoğan, A., Boynueyri, D., Çay, V.V. Determination of Abrasion Resistance of Thin Film Coated Cutting Tools with Micro-Scale Wear Test International Engineering and Natural Sciences Conference (IENSC) 2019: pp. $1005-1013$.

https://doi.org/10.1016/j.surfcoat.2012.08.077

7. Lind, L., Peetsalu, P., Sergejev, F. Wear of Different PVD Coatings at Industrial Fine-Blanking Field Tests Materials Science (Medžiagotyra) 21 (3) 2015: pp. 343-348. https://doi.org/10.5755/j01.ms.21.3.7249

8. Paiva, J.M., Fox-Rabinovich, G., Locks Junior, E., Stolf, P., Seid Ahmed, Y., Matos Martins, M., Veldhuis, S. Tribological And Wear Performance of Nanocomposite PVD Hard Coatings Deposited on Aluminum Die Casting Tool Materials 11 (3) 2018: pp. 358-372. https://doi.org/10.3390/ma11030358

9. Beake, B.D., Endrino, J.L., $\quad$ Kimpton, C., $\quad$ FoxRabinovich, G.S., Veldhuis, S.C. Elevated Temperature Repetitive Micro-Scratch Testing of AlCrN, TiAlN and AlTiN PVD Coatings International Journal of Refractory Metals and Hard Materials 69 2017: pp. 215-226. https://doi.org/10.1016/j.ijrmhm.2017.08.017

10. Adesina, A.Y., Gasem, Z.M., Mohammed, A.S. Comparative Investigation and Characterization of The Scratch and Wear Resistance Behavior of TiN, CrN, AlTiN and AlCrN Cathodic Arc PVD Coatings Arabian Journal for Science and Engineering 44 (12) 2019: pp. 10355-10371. https://doi.org/10.1007/s13369-019-04038-8

11. Falsafein, M., Ashrafizadeh, F., Kheirandish, A. Influence of Thickness on Adhesion of Nanostructured Multilayer
CRN/CrAlN Coatings to Stainless Steel Substrate Surfaces and Interfaces 13 2018: pp. 178-185.

https://doi.org/10.1016/j.surfin.2018.09.009

12. Kohlscheen, J., Bareiss, C. Effect of Hexagonal Phase Content on Wear Behaviour of Altin Arc PVD Coatings Coatings 8 (2) 2018: pp. $72-80$. https://doi.org/10.3390/coatings8020072

13. Birol, Y. Sliding Wear of $\mathrm{CrN}, \mathrm{AlCrN}$ and AlTiN Coated AISI H13 Hot Work Tool Steels in Aluminium Extrusion Tribology International 57 2013: pp. 101-106. https://doi.org/10.1016/j.triboint.2012.07.023

14. Birol, Y., İsler, D. Response to Thermal Cycling of CAPVD (Al, Cr) N-Coated Hot Work Tool Steel Surface and Coatings Technology 205 (2) 2010: pp. 275-280. https://doi.org/10.1016/j.surfcoat.2010.06.038

15. Çalışkan, H. Effect of Test Parameters on The MicroAbrasion Behavior of PVD CrN Coatings Measurement 55 2014: pp. $444-451$. https://doi.org/10.1016/j.measurement.2014.05.036

16. Kassman, Å., Jacobson, S., Erickson, L., Hedenqvist, P., Olsson, M. A New Test Method for The Intrinsic Abrasion Resistance of Thin Coatings Surface and Coatings Technology 50 (1) 1991: pp. 75-84. https://doi.org/10.1016/0257-8972(91)90196-4

17. Gant, A.J., Gee, M.G. A Review Of Micro-Scale Abrasion Testing Journal of Physics D: Applied Physics 44 (7) 2011: pp. 073001. https://doi.org/10.1088/0022-3727/44/7/073001

18. Prabakaran, V., Ilaiyavel, S., Suresh Prabhu, P., Thambu, S.S. Wear Characteristics of AlCrN Coating on AISI 410 Steel by The Ball-Cratering Test Method Industrial Lubrication and Tribology 69 (4) 2017: pp. 484-490. https://doi.org/10.1108/ILT-05-2016-0107

19. Umanskyi, O., Poliarus, O., Ukrainets, M., Antonov, M., Hussainova, I. High Temperature Sliding Wear of NiAlBased Coatings Reinforced by Borides Materials Science (Medžiagotyra) 22 (1) 2016: pp. 49-53. https://doi.org/10.5755/j01.ms.22.1.8093

20. Çalışkan, H., Erdoğan, A., Panjan, P., Gök, M.S., Karaoğlanl, A.C. Micro-Abrasion Wear Testing of Multilayer Nanocomposite TiAlSiN/TiSiN/TiAlN Hard Coatings Deposited on AISI H11 Steel Materiali in Tehnologije/Materials and Technology 47 (5) 2013: pp. $563-568$.

21. Richter, J. Micro-Scale Abrasion Testing of PVD Tin Coatings on Conventional and Nonledeburitic High-Speed Steels Wear $257(3-4)$ 2004: pp. 304-310. https://doi.org/10.1016/j.wear.2003.12.016

22. Mo, J.L., Zhu, M.H., Leyland, A., Matthews, A. Impact Wear and Abrasion Resistance of $\mathrm{CrN}, \mathrm{AlCrN}$ and AlTiN PVD Coatings Surface and Coatings Technology 215 2013: pp. $170-177$. https://doi.org/10.1016/j.surfcoat.2012.08.077

23. Batista, J.C.A., Godoy, C., Matthews, A. Micro-Scale Abrasive Wear Testing of Duplex and Non-Duplex (SingleLayered) PVD (Ti, Al) N, TiN and Cr-N Coatings Tribology International 35 (6) 2002: pp. 363-372. https://doi.org/10.1016/S0301-679X(02)00017-8

24. Allsopp, D.N, Hutchings, I.M. Micro-Scale Abrasion and Scratch Response of PVD Coatings at Elevated Temperatures Wear 251 2001: pp. 1308-1314. https://doi.org/10.1016/S0043-1648(01)00755-4

25. Mercado-Solis, R.D., Mata-Maldonado, J.G., QuinonesSalinas, M.A., Rodriguez-de-Anda, E., Servín- 
Castañeda, R. Micro-Scale Abrasive Wear Testing of CrN Duplex PVD Coating on Pre-Nitrided Tool Steel Materials Research 20 (4) 2017: pp. 1092-1102. https://doi.org/10.1590/1980-5373-mr-2016-0757

26. Erdoğan, A., Altaş, E. Experimental Study on MicroAbrasion Behavior of Hard Coatings: The Role of Load, Sliding Distance and Abrasive Particle Size Materials Research Express 6 (11) 2019: pp. 116430. https://doi.org/10.1088/2053-1591/ab47ad

27. Willmann, H., Mayrhofer, P.H., $\quad$ Persson, P.Å., Reiter, A.E., Hultman, L., Mitterer, C. Thermal Stability of Al-Cr-N Hard Coatings Scripta Materialia 54 (11) 2006: pp. $1847-1851$.

https://doi.org/10.1016/j.scriptamat.2006.02.023

28. Beake, B.D., Smith, J.F., Gray, A., Fox-Rabinovich, G.S., Veldhuis, S.C., Endrino, J.L. Investigating The Correlation Between Nano-Impact Fracture Resistance and Hardness/Modulus Ratio From Nanoindentation at $25-500{ }^{\circ} \mathrm{C}$ and the Fracture Resistance and Lifetime of Cutting Tools with Ti1- xAlxN ( $x=0.5$ and 0.67) PVD Coatings in Milling Operations Surface and Coatings Technology 201 (8) 2007: pp. 4585-4593. https://doi.org/10.1016/j.surfcoat.2006.09.118

29. Carvalho, S., Rebouta, L., Ribeiro, E., Vaz, F., Denannot, M.F., Pacaud, J., Alves, E. Microstructure of (Ti, Si, Al) N Nanocomposite Coating Surface and Coatings Technology 177 2004: pp. 369-375. https://doi.org/10.1016/j.surfcoat.2003.09.029

30. Prengel, H.G., $\quad$ Santhanam, A.T., Penich, R.M., Jindal, P.C., Wendt, K.H. Advanced PVD-TiAlN Coatings on Carbide and Cermet Cutting Tools Surface and Coatings Technology 94 1997: pp. 597-602. https://doi.org/10.1016/S0257-8972(97)00503-3

31. Günen, A., Gök, M.S., Erdoğan, A., Kurt, B., Orhan, N. Investigation of Microabrasion Wear Behavior of Boronized Stainless Steel With Nanoboron Powders Tribology Transactions 56 (3) 2013: pp. 400-409. https://doi.org/10.1080/10402004.2012.756566

32. Vargas-Gonzalez, L., Speyer, R.F., Campbell, J. Flexural Strength, Fracture Toughness, and Hardness of Silicon Carbide and Boron Carbide Armor Ceramics International Journal of Applied Ceramic Technology 7 (5) 2010: pp. 643-651. https://doi.org/10.1111/j.1744-7402.2010.02501.x

33. Mo, J.L., Zhu, M.H., Leyland, A., Matthews, A. Impact Wear and Abrasion Resistance of CrN, AlCrN and AlTiN PVD Coatings Surface and Coatings Technology 215 2013: pp. $170-177$. https://doi.org/10.1016/j.surfcoat.2012.08.077

34. Günen, A., Kanca, E., Demir, M., Er, Y., Sağlam, G., Gök, M.S. Microabrasion Wear Behavior of Fast-Borided Steel Tooth Drill Bits Tribology Transactions 60 (2) 2017: pp. $267-275$. https://doi.org/10.1080/10402004.2016.1159359

35. Gee, M., Gant, A.J., Hutchings, I.M., Kusano, Y., Schiffman, K., Van Acker, K., Plint, G. Results from an Interlaboratory Exercise to Validate the Micro-Scale Abrasion Test Wear $259(1-6)$ 2005: pp. 27-35. https://doi.org/10.1016/j.wear.2005.02.092

36. Cassar, G., Banfield, S., Wilson, J.A.B., Housden, J., Matthews, A., Leyland, A. Micro-Abrasion Wear Testing of Triode Plasma Diffusion and Duplex Treated Ti-6Al-4V Alloy Wear 274 2012: pp. 377-387. https://doi.org/10.1016/j.wear.2011.10.002

37. Trezona, R.I., Allsopp, D.N., Hutchings, I.M. Transitions Between Two-Body and Three-Body Abrasive Wear: Influence of Test Conditions in The Microscale Abrasive Wear Test Wear 225 1999: pp. 205-214. https://doi.org/10.1016/S0043-1648(98)00358-5

38. Shipway, P.H., Hogg, J.J. Wear of Bulk Ceramics in MicroScale Abrasion-The Role of Abrasive Shape and Hardness and its Relevance to Testing of Ceramic Coatings Wear 263 (7-12) 2007: pp. 887-895. https://doi.org/10.1016/j.wear.2006.11.028

39. Brostow, W., Deborde, J.L., Jaklewicz, M., Olszynski, P. Tribology with Emphasis on Polymers: Friction, Scratch Resistance and Wear Journal of Materials Education 25 (4/6) 2003: pp. 119-132.

40. Günen, A., Küçük, Y., Er, Y., Çay, V.V., Öge, M., Gök, M.S. Effect of The Powder Particle Size on The Wear Behavior of Boronized AISI 304 Stainless Steel Materials Testing 57 (5) 2015: pp. $468-473$. https://doi.org/10.3139/120.110732 you give appropriate credit to the original author(s) and the source, provide a link to the Creative Commons license, and indicate if changes were made. 